The Society for Healthcare Epidemiology of America

President

President-Elect

Vice President

Past President

SECRETARY
Peter A Gross, MD/Hackensack, New Jersey Bryan P. Simmons, MD/Memphis, Tennessee William J. Martone, MD/Atlanta, Georgia

Donald E. Craven, MD/Boston, Massachusetts

Dale N. Gerding, MD/Chicago, Illinois
Treasurer

COUNCILOR

Couvcilor Leigh G. Donowitz, MD/Charlottesville, Virginia

Councilor Timothy W. Lane, MD/Greensboro, N. Carolina

Councilor H. Gunner Deery, II, MD/Petoskey, Michigan

\title{
Committee Hard at Work; Membership Reaches 1,000
}

I became Chairman of the Membership Committee in January of 1994. I am grateful that William Mar-tone, MD, agreed to stay on the Committee after his successful tenure as Chairman. Under Dr. Mar-tone's leadership, the Committee implemented much of the Board's 199195 strategic plan, including exhibiting at other meetings, developing a very professional and attractive exhibit booth, redesigning the SHEA membership brochure and application form, expanding the Society by 100 new members per year, and developing the membership certificate.

As this 5-year strategic plan concludes in 1995, we need to review goals not achieved and look for new challenges and opportunities to enhance membership and improve its value. One of our greatest challenges is to increase the number of non-infectious diseases professionals in SHEA The 5-year plan charged that one third of new members should be non-infectious disease professionals. Historically, the non-infectious disease group that we have recruited has included the many surgeons and pathologists who serve as infection control committee chairpersons. This should continue; however, current and future partners in Healthcare Epidemiology should include professionals involved in quality performance and informatics. These professionals will be valuable partners as we help shape the future of healthcare, and we want them to be part of our organization. We need to maximize the membership and participation of epidemiologists in community hospitals and healthcare plans. We need to promote the practical value of membership, which includes networking, educational opportunities, and our journal; expanding our image and membership internationally; and developing other services that enhance the value of membership.

Another challenge is the continued struggle of asking, "Who are we?" At its March 1994 meeting, the Board endorsed a mechanism proposed by the Committee to consider for membership selected nondoctoral candidates who have made significant contributions to the field of healthcare epidemiology. The proposal will be voted on at the Annual Meeting in 1995. I urge you to review the proposal and be sure to vote!

Our current project is the third SHEA membership survey, which

will be sent out this year. We are updating the 1991 survey form. Some additional items will include Fax number, E-mail information, assessment of members' needs re: quality performance and informatics, educational opportunities, assessment of current pressures to assume quality improvement activities, and SHEA Annual Meeting data. The Committee welcomes any suggestions from the membership as we complete our development of the survey form. Please help to make the survey a success by carefully completing the survey form and returning it promptly.

I would like to thank the Membership Committee for their continued help and counsel. I look forward to meeting our challenges (ie, opportunities) during my tenure as Membership Committee Chairperson.-H. Gunner Deery, M D , FACP, M embership Committee Chairperson.

\section{Infection Control in Switzerland}

Surveillance of nosocomial infections is not a legal obligation in Switzerland; thus, hospital infection control is not mandatory in my country. However, hospital hygiene, as a discipline, has existed for many years in European countries; its major focus is the prevention of nosocomial infections associated with patient care support services and the hospital and surgical environment. Traditionally, hospital pharmacists or microbiologists were responsible for hospital hygiene in
Switzerland.

Patient-oriented infection control activities started recently in Swiss hospitals. All five university hospitals have developed infection control programs, funded by the hospital, with patient-oriented surveillance for nosocomial infections. The directors of these programs are physicians trained in infectious diseases in Switzerland and the United States.-D idier Pittet, M D, M S, Geneva U niversity Hospital, Switzerland 


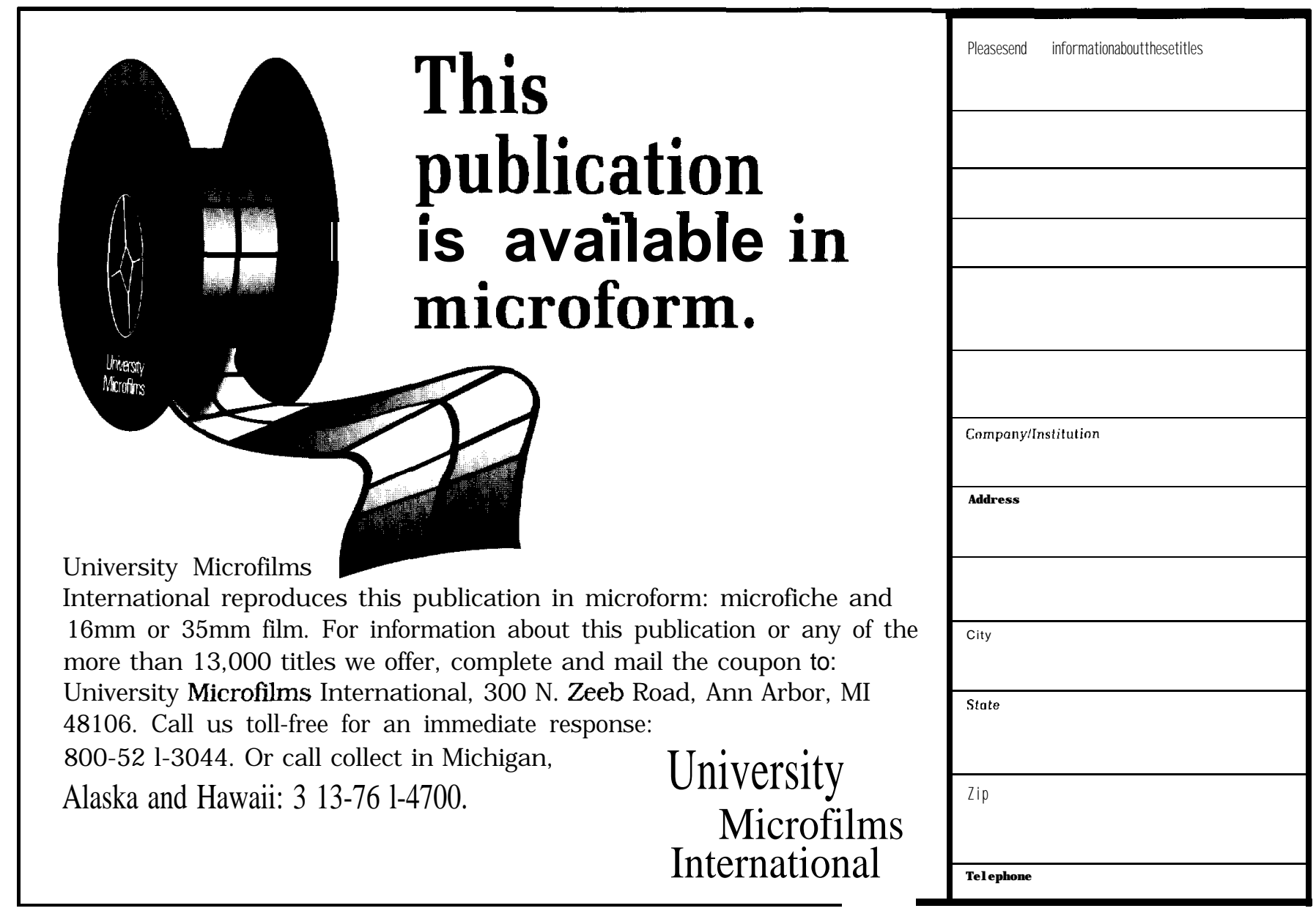

\section{Classified Marketplace}

re • sponse \ri-`spän(t)s\

That's what you want from a classified ad. And Classified Marketplace lets you reach the audience you want-cost effectively-to get you the response you need.

- Employment Opportunities

- Positions Wanted

- Meetings

- Services
- Educational Opportunities

- For Sale/For Rent

- Miscellaneous

- Wanted

\section{RATES}

Typesetting Available

Line Advertising - \$23 per line,

$\$ 138$ minimum

Classified advertising is non-commissionable

\section{Contact our Classified Advertising Representative}

for help in placing your customized ad message: 


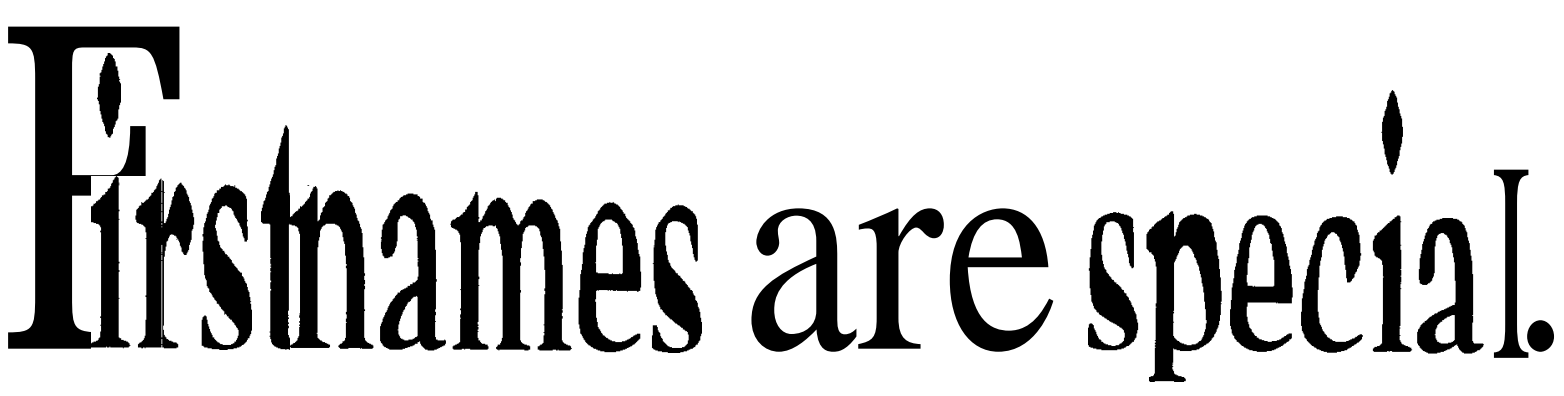

TheDover@brand name is

synonymous with quality and

innovation. Our testing

techniques are geared toward

the way urological products are

actually used by medical

professionals like you. We tested

the new large-capacity Measurit ${ }^{\circledR}$

urine meter with this concept

in mind because we never

compromise our attention to

detail in the design and

manufacture of our urologicals.

We never forget that the people

who use our products and need our

products are people just like us. 